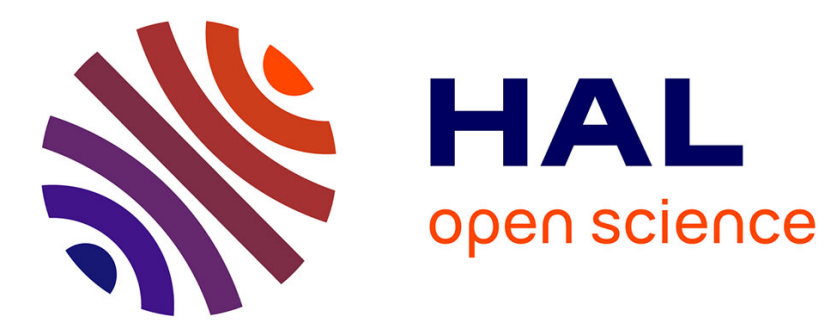

\title{
Dynamic Strength of Fiber Glass Shells
}

M. Syrunin, A. Fedorenko, A. Ivanov

\section{To cite this version:}

M. Syrunin, A. Fedorenko, A. Ivanov. Dynamic Strength of Fiber Glass Shells. Journal de Physique IV Proceedings, 1997, 07 (C3), pp.C3-517-C3-521. 10.1051/jp4:1997389 jpa-00255546

\section{HAL Id: jpa-00255546 https://hal.science/jpa-00255546}

Submitted on 1 Jan 1997

HAL is a multi-disciplinary open access archive for the deposit and dissemination of scientific research documents, whether they are published or not. The documents may come from teaching and research institutions in France or abroad, or from public or private research centers.
L'archive ouverte pluridisciplinaire HAL, est destinée au dépôt et à la diffusion de documents scientifiques de niveau recherche, publiés ou non, émanant des établissements d'enseignement et de recherche français ou étrangers, des laboratoires publics ou privés. 


\title{
Dynamic Strength of Fiber Glass Shells
}

\author{
M.A. Syrunin, A.G. Fedorenko and A.G. Ivanov \\ Russian Federal Nuclear Center-VNIIEF, Sarov, Nizhni Novgorod Region 607190, Russia
}

\begin{abstract}
This paper presents generalization of results, obtained by experimental investigations of dynamic response, strength, and load-bearing ability of cylindrical and spherical shells, manufactured from composite materials on the basis of fiber glass, under loading them by explosion of compact high-explosive charges on the inside. The paper describes mechanisms and criteria of destruction of such shells, methods to improve their specific load-bearing ability. Results of experiments concerning investigation of dependence of specific load-bearing ability on loading rate, absolute sizes of samples, structural and technological peculiarities of the material are considered. On the basis of considered results it is suggested to use limiting strains of the most stressed composite layers as the general criterion of dynamic strength for materials of this class. We draw a conclusion that application of fiber glasses in load-bearing shells of protective structures has considerable promise.
\end{abstract}

\begin{abstract}
Résumé. On généralise les résultats obtenus dans les expériences étudiant la réponse dynamique, la résistance et la capacité portante des enveloppes cylindriques et sphériques en composites sur la base des fibres de verre mis en charge par les explosives compacts explosant en dedans les enveloppes. Les mécanismes et les critères décrivant la rupture des enveloppes de ce type, les procédés permettant d'augmenter leur capacité portante spécifique sont présentés. Les résultats obtenus dans les expériences étudiant la capacité portante spécifique en fonction de la vitesse de mise en charge, des dimensions absolues des échantillons, des particularités de la structure et de la technologie des matériaux sont analysés. A partir de ces résultats on propose d'utiliser la déformation maximale dans les couches de composite les plus contraintes comme un critère général pour la résistance dynamique propre à cette classe des matériaux. On tire la conclusion que le plastique renforcé à la fibre de verre peut être appliquer avantageusement comme une enveloppe de force pour les constructions antidétonantes.
\end{abstract}

Requirements of the present engineering cause the necessity to search for and develop firmer and more reliable structural materials. Also areas of application of known materials have been expanded by comprehensive study of their properties. Important group of materials, which allow to develop structures with new and sometimes unique properties, is the group of composites based on high-strength fibers with small diameters. Wide opportunities to vary compositions and structures of such materials determine high significance of experimental study of properties and limiting criteria of destruction, which are necessary for strength calculations.

The paper presents a brief review of experimental works devoted to study of dynamic strengths of shells from coiled composites basing mainly on fiber glass. Loading of the shells was conducted by detonation of compact high explosive (HE) charge in their cavities. This problem rises in practice when developing protective devices and vessels (i.e. containers or explosive chambers ) to prevent the environment from harmful effects of explosions [1-5].

The following main conclusions were drawn in the first experimental works $[1,2]$ on study of response and destruction of cylindrical shells from fiber glass basing on glass cloth impregnated with polymeric binder during $\mathrm{HE}$ charge explosion in the geometrical center.

The character of shells strains is elastic up to destruction. The elasticity modulus (ring modulus) does not depend on the strain velocity in the wide range $10^{-3}-1,5^{*} 10^{3} 1 / \mathrm{s}$. However, the limiting circular strains under conditions of dynamic loads are two times higher than under static loads.

One has not observed influence of the scale change on strength and deformability of the shells, which are similar geometrically and up to 4.4 times differ in sizes. Absence of the scale factor of the strength 
drop having energetic nature [3] can be explained by similar structure of the composite and its invariability in the material of shells having different diameters of the basic element that is fiber glass $[1,3,4]$.

In comparison with steel shells [2] fiber glass shells have some advantages associated with variations in energy-intensity (i.e. energy absorption under deformation) of these materials under similar specific loads $\xi$ (where $\xi$ - ratios between the TNT equivalent of explosion and mass of the shell ). So, if fiber glass is subjected to strains up to $4 \%$, the steel shell with the yield limit of $250 \mathrm{MPa}$ experiences plastic strains up to $30 \%$. This can be dangerous for its strength due to sensitivity of steel plasticity to external and internal defects.

Besides, it has been revealed that fiber glasses have low sensitivity to both initial and formed defects. They have high resistance to growth of a crack. Cracks in a laminated package of the composite have ramified and multiple structure. The material is loosened and there are no actually formations of harmful large fragments, flying away with high velocities, when the shell is destructed by internal explosion in the air and through cracks are caused. Catastrophic destruction is typical for steel shells under similar conditions of loading. Fragments with high masses are accelerated up to velocities of $\geq 100 \mathrm{~m} / \mathrm{s}$ and have high piercing ability.

Some peculiarities of loading and dynamic response of fiber glass shells were revealed [6-8]. So. when the shock wave and the flow of explosion products are reflected from the shell wall, the radial pulse, effecting on it, is distributed along the generatrix length proportionally with projection of gasdynamic pulse of explosion on the normal to the internal surface of the shell. As this takes place, so axis-symmetrical forms of vibrations are excited that maximum circular strains, reached in the first phase of expansion in the zone with the width of $\sim \mathrm{R}$, keep to be maximum during the whole reaction, if stability of axis-symmetrical forms is not disturbed. Meridional bending and tension are significantly less than maximum circular strains.

At the same time, the shell filled up in its initial state with air, is destructed after one or several phases of tension-compression, if circular strains in the first phase of expansion are significantly less than the limiting strains for the material. Analysis of reasons of such load-bearing ability drop showed that the principal reason of this phenomena is parametric instability of axis-symmetrical shapes of vibrations and transition from axis-symmetrical radial movement to bending movement. Such a mechanism at certain level of destruction will cause local increases of voltage and formation of meridional cracks with periodicity depending on the specific thickness of the shell along the length of the circle in the most loaded zone with the width of $\sim R$ (fig.1a). Possibility of such energy pumping from one form of vibrations to the other form can be explained by low damping of them in air (contrary to response to explosion in water inside of the shell), existence of initial imperfections of a shape and properties of the material, and by incomplete symmetry of loading [6-8].

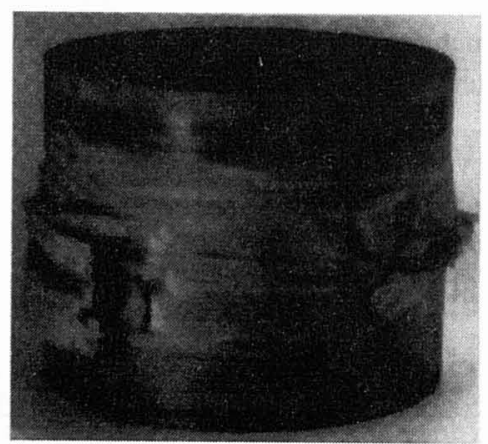

a)

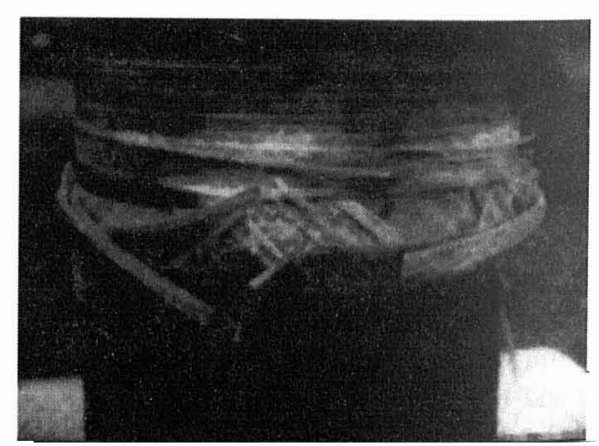

b)

Figure1: States of destructed shells having the cloth basis (a) and the fiber basis (b).

It was found out that significant increase of circular strains and specific explosive load can be reached by reinforcement of fiber glass with a steel layer on the inside. There was experimentally determined relation between thicknesses of fiber glass and steel (steel layer with thickness of $\geq 1 / 8$ to 
thickness of fiber glass), when quick damping of radial vibrations of the shell took place, and that was the reason of achievement of mentioned increase [9]. In work [10] such effect was achieved after addition of a copper foil layer adjacent to fiber glass.

A glass thread is the basic load-bearing element of fiber glass, which determines limiting strength and strain properties of the laminated package under conditions of pulse loads. This is experimentally confirmed in [11], where the shells, manufactured by coiling of glass cloth and coal cloth on a cylindrical frame without impregnation with a binder, are tested. Influence of a fiber type and properties of a binder on the dynamic strength of composite shells was studied in work [12]. In this work the authors loaded by explosion the shells manufactured by coiling of bands from braids basing on fiber glass and organic fiber impregnated with polymeric binder with different elasticity. Change of the binder elasticity had no influence on their load-bearing abilities. It follows from significant differences (approximately by an order) between both acoustic resistances and energy absorptions of the fiber and the binder. This determines contribution of each component to the total strength of the composite.

Polymeric matrix in the composite, produced by coiling, fulfills the role of a binder between layers from threads (layers can be in the form of glass cloth, bands from many threads, bunches of fibers, etc.), it provides their joint work and continuity of all laminated package of the material. Features of the binder determine mainly just interlayer (in the radial direction) dynamic (spall) strength of the composite [13].

It is evident that abundance of types of fibers and available structures of layered reinforcement causes complication of the problem to make an optimum selection of them with the purpose to provide maximum dynamic strength of the shell. In [12] for selection of elastic fiber of composite material under pulse loading the experts proposed the criterion (instead of the specific strength for static conditions of loading) consisting in the product of the sound velocity in fiber (c) by its limiting elastic deformation of dynamic tension $(\varepsilon)$. It is numerically equal to the initial limiting rate of the ring element expansion, when it is still able to avoid breaks. With the use of this criterion it is possible to describe quantitative ratio of specific load-bearing abilities of shells basing on glass fiber, coal fiber, and organic fiber with similar scheme of layers coiling. Confirmation of this criterion efficiency was also obtained in [14] when studying shells with similar coiling schemes, but with combination of glass fiber, organic fiber, and coal fiber, including up to three types of fiber in one package. Addition of high-modular coal fibers with less value of $\mathbf{c} \times \varepsilon$ in layers, manufactured by coiling of glass and organic threads, does not allow to increase the specific explosive load for such shells in comparison with shells basing on only glass fibers or organic fibers. According to this criterion, taking into account the cost, high-modular glass fibers are the most preferable material of composite shells, loaded by single internal explosion [15].

Important factor to provide high specific characteristics of the material strength is a structure of the laminated package of the composite. This structure is determined by the reinforcement scheme. It is evident that in fiber glass, basing on glass cloth, threads are bent due to frequent interlacings. That is why in the unloaded state they have preliminary stresses (besides stresses caused by tension when coiling and shrinkage stresses during the binder rejection). This reduces the material strength. Besides, it is difficult to form a shell with double curvature by coiling of cloth (for example, when coiling spherical or ellipsoidal shells).

The wide range of reinforcement schemes can be obtained by a shell coiling of the "cocoon» type using threads or rather narrow bands, formed from threads or braids. Here the fiber strength reserves are released by straightening and reduction of the damage extent of its surface due to decrease of number of technological procedures in the manufacture process.

Work [16] presents the influence assessment and the scheme of fiber glass shell reinforcement, which is the most optimum among tested schemes. This scheme provides the highest specific load-bearing ability with parameter $\xi$ under internal explosive loading. There were investigations of shells, which were similar in sizes and manufactured by coiling of helical layers, ring layers or interchange of helical and ring layers with different ratios of thicknesses (1:1 and 1:2.5). Conclusion was made that the most preferable is the scheme of reinforcement by interchange of helical and ring layers with similar thicknesses. There were found out significant differences in responses and characters of destructions of samples with different structures. So, only helical coiling with angle of $\pm 30^{\circ}$ (i.e. the angle between the direction of the band arrangement and the shell generatrix) causes the possibility of residual strains and formation of cask-like shape due to mutual displacements of bands during the binder destruction. Only ring coiling (with the 
angle close to $90^{\circ}$ ) results mainly in ring cracks due to low strength of the binder. The firmest type of reinforcement is destructed like glass cloth-based samples (fig.la). However, meridional cracks are less expressed in them, but convexities of loosened material, located at regular intervals, are formed (fig. lb). Also destruction takes place not in the first phase of expansion, but in the process of the shell vibrations. These conclusions are confirmed in [17], where wider range of reinforcement structures is considered Besides, it was revealed that one-type schemes of reinforcement (i.e. using only helical layers or only ring layers) had 1.5-2 times less dynamic load-bearing ability in comparison with the most preferable structure having interchange of helical and ring layers. As this took place, the compared structures had similar calculated strengths in the ring direction.

It is shown in [18-20] that when providing the shell destruction in the first phase of radial expansion due to increase of explosive load for the shell filled up with air, water, or reinforced by a steel layer the limiting strains of circular tension is $4,8 \pm 0,4 \%$. It corresponds to the limiting strains of tension of used high-modular glass fiber. The shells with helical-ring reinforcement were tested with varying of the helical coiling angle $\pm 35-65^{\circ}$. In such a way there was shown insensitiveness of the limiting strains during dynamic tension and destruction of the tensest composite ring layers caused by change of adjacent helical layers orientation in the specified range. The same conclusion was made in work [21] for shells from fiber glass basing on fibers having different compositions. Consequently, the limiting strains of a fiber can be a criterion of the coiling fiber glass strength in the investigated range of reinforcement schemes, realized stressed states of the material when filling up the shell cavities with air and water, and at strain velocities of $\sim 10^{2}-10^{3} 1 / \mathrm{c}$.

Data from [22] and investigations of fiber glass spall strength [13] confirm the conclusion on invariability of value of the limiting strains of glass fibers in the composite in the wide range of strains rates from $10^{2}$ to $10^{5} 1 / \mathrm{s}$. At the strains velocities less than $10^{2} 1 / \mathrm{s}$ there was observed decrease of the limiting strains for both samples from fiber composites and samples basing on glass cloth [19,22]. This should be taken into account when designing large-size shells subjected to pulse loading and strained slower, and when operating designs from composites subjected to static loads.

Results of spherical fiber glass shells testing [23,24] are important in principle. These results show: that there is no decrease of the limiting deformability and strength of the composite material, when two. axial stressed state is realized in comparison with the case close to one-axial dynamic stressed state in cylindrical shells from similar composite. This allows to reach more than threefold increase of specific load-bearing ability of the explosive chamber having a spherical shape (fig.2a) in comparison with the chamber having the same diameter ( $\varnothing 500 \mathrm{~mm}$ ) and a cylindrical shape (fig.2b) for the case of compact HE charge explosion. The limiting value of relation between HE mass and mass of two-layer (namely, fiber glass reinforced with a thin steel layer) body of the chamber, having a spherical shape, can reach $\sim 0.05$. For steel shells the transition from the cylindrical shape to the spherical shape causes drop (in 3-5 times) of their limiting deformability in the plastic area and drop of their specific strength [25]. Besides, for steels there is possibility of a manifestation of strong scale effects having the energetic nature $[3,25]$ when turning from small-scale models to actual large-scale designs. This can cause their destruction even at elastic strains. Due to these reasons the explosion-proof designs basing on fiber glass are lighter by order than similar (in the TNT equivalent of confined explosion) designs from steel.

Thus, the presented generalized results of experimental works show that the shells from fiber glass have: high specific strength, which increases under dynamic conditions of loading with practically elastic behaviour of the material up to destruction; low sensitivity to defects and non-catastrophic (nonthreshold) character of destruction; resistance to strong scale effects of strength decrease, having the energetic nature, as sizes increase (due to constancy of the load-bearing fibers diameters of the large-scale design and the small-scale model); high manufacturability and repetition of the material properties during a rather economical manufacture of the rotation shells by the coiling method. Also for these materials high stability of properties in time is typical during effects of harmful factors (i.e. effects of climatic factors and agressive media) [26].

All metioned properties of fiber glass allow to develop light and reliable explosion-proof designs on their basis. 


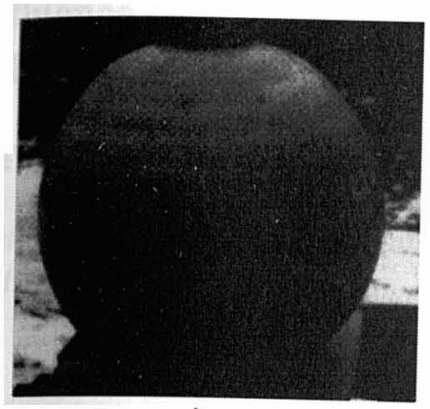

a)

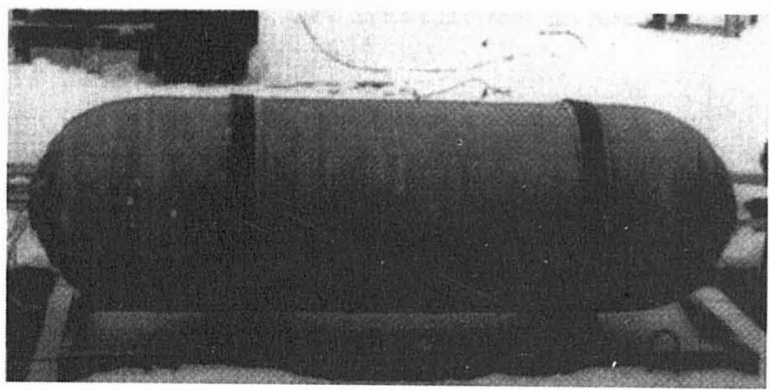

b)

Figure 2: Explosive chambers of the spherical shape (a) and the cylindrical shape (b) after loading by explosion with energy of $1.4 \mathrm{~kg}$ of the TNT equivalent.

\section{References}

[1] Ryzhanski V.A., Mineev V.N., Ivanov A.G. et al., Mechanics of polimers 2(1978) 283-289.

[2] Tsypkin V.I., Rusak V.N., Shitov A.T., Ivanov A.G., Mechanics of komposite materials 2(1981) 249.

[3] A.G. Ivanov, S.A. Novikov, V.A. Sinitsyn, V.I. Tsypkin Applied problems of strength and plasticity 29(1985) 3-21.

[4] A.G. Ivanov, V.I. Tsypkin. Mechanics of composite materials 3(1987) 472-480.

[5] Lugovoi P.Z., Applied mechanics 26(1990) 3-20.

[6] Fedorenko A.G., Tsypkin V.I., Ivanov A.G. et al., Mechanics of komposite materials 1(1983) 90-94.

[7] Fedorenko A.G., Tsypkin V.I., Ivanov A.G. et al., Mechanics of komposite materials 4(1986) 658-664.

[8] Fedorenko A.G., Syrunin M.A., Ivanov A.G., Mechanics of komposite materials 3(1989) 425-430.

[9] Tsypkin V.I., Rusak V.N., Ivanov A.G., Mechanics of komposite materials 5(1987) 833-838.

[10] Aseev A.V., Makarov G.E., Stepanenko S.V., Applied mechanics and technikal physics 3(1992) 140.

[11] Tsypkin V.I., Rusak V.N., Ivanov A.G., Mechanics of komposite materials 1(1986) 161-163.

[12] Fedorenko A.G., Tsypkin V.I., Syrunin M.A. et al., Mechanics of komposite materials 2(1988) 306.

[13] Ivanov A.G., Syrunin M.A., Fedorenko A.G., "Spall strength of winding glass-reinforced plastic in three principal directions", Second international symposium on intense dynamic loading and its effects, Chengdu, China 9-12 June 1992 (1992) p.365.

[14] Syrunin M.A., Fedorenko A.G., "Dinamic strength of combined composite materials", Dielektric materials under extreme conditions, I USSR Meeting, Suzdal 22-26 January 1990 (1990) pp.425-430.

[15] Ivanov A.G., Fedorenko A.G., Nuclear energy 75(1993) 45-48.

[16] Syrunin M.A., Fedorenko A.G., Shitov A.T., Physics of combustion and exsplosion 4(1989) 108-115.

[17] Fedorenko A.G., Syrunin M.A., Ivanov A.G., Mechanics of komposite materials 4(1991) 631-640.

[18] Vorontsova O.S., Syrunin M.A., Fedorenko A.G., Mechanics of komposite materials 4(1987) 642646.

[19] Syrunin M.A., Fedorenko A.G., Ivanov A.G., Physics of combustion and exsplosion 2(1992) 87-93.

[20] Ivanov A.G., Syrunin M.A., Fedorenko A.G., Applied mechanics and technikal physics 4(1992) 130135 .

[21] Syrunin M.A., Fedorenko A.G., Ivanov A.G., Applied mechanics and technikal physics 36(1995) 141-145.

[22] Kornev V.M., Demeshkin A.G. "Dynamik fracture of unidirectional composites at hite-rate strain", 3rd International Conference on Mehanical and Physical Behaviour of Materials under Dynamic Loading, Strasbourg, France (J.Phys. IV France, 1991) C3-681-C-3 686.

[23] A.G. Fedorenko, M.A. Syrunin, A.G. Ivanov Applied mechanics and technical physics 1(1993) 126133.

[24] A.G. Fedorenko, M.A. Syrunin, A.G. Ivanov Physics of combustion and explosion 31(1995) 93-99.

[25] A.G. Ivanov, V.N. Mineev Physics of combustion and explosion 5(1979) 78-95.

[26] Gunjaev G.M. Structure and properties of polimeric fiber composites (Moskov, Chemistry, 1981) p229. 